\title{
The most effective pollinator revisited: pollen dynamics in a spring-flowering herb
}

\author{
Marcin Zych • Jan Goldstein • Katarzyna Roguz • \\ Małgorzata Stpiczyńska
}

Received: 7 May 2012/ Accepted: 1 January 2013/Published online: 22 January 2013

(c) The Author(s) 2013. This article is published with open access at Springerlink.com

\begin{abstract}
Most flowers are visited by a wide range of potential pollinators. However, their efficiency in pollen removal and deposition, and other behavioural factors affecting pollination effectiveness may greatly differ among taxa, and even individuals. Fritillary (Fritillaria meleagris L., Liliaceae) is a spring-flowering, critically endangered plant in the Polish flora, red-listed in most of the European countries of its range. Based on indirect evidence, that is, body pollen loads, visitation frequency and seasonal abundance, it is estimated that its key pollinators are queen bumblebees, but, as shown in the literature, the largest Fritillaria pollen loads are carried by solitary bees. To study pollinator effectiveness for floral visitors to $F$. meleagris, we performed a garden experiment, where we analysed pollen deposition and assessed pollen removal per single flowervisit in the plant. Similarly to field conditions reported in the literature, our experimental plants were serviced by nectarseeking bumblebee queens and two taxa of solitary bees, small pollen-collecting Andrena and large, nectar-seeking Anthophora males. When "quality" component was addressed, despite the character of visits, insects from all groups deposited more pollen than was found on unvisited flowers, but they did not differ significantly from each other in pollen deposition on virgin stigmas. We also found some differences in pollen removal both within- and among-visitor species and control flowers, unfortunately due to extremely high variation of the results they were all statistically insignificant. However, when "quantity" component of insect
\end{abstract}

Handling Editor: Neal Williams.

M. Zych $(\bowtie) \cdot$ J. Goldstein $\cdot$ K. Roguz $\cdot$ M. Stpiczyńska

University of Warsaw Botanic Garden,

Aleje Ujazdowskie 4, 00-478 Warsaw, Poland

e-mail: mzych@biol.uw.edu.pl performance was concerned, we observed that over $81 \%$ of visits were by bumblebees. Bombus queens stayed on flowers significantly less time than small Andrena individuals (13\% of recorded visits) and equally long as Anthophora males (only $6 \%$ of visits). We conclude that although all the visitor groups can pollinate the flowers of $F$. meleagris, bumblebee queens indeed proved to be the most effective pollinators of the plant, when both quality and quantity components of pollination are concerned.

Keywords Bumblebees - Effectiveness - Fritillaria meleagris $\cdot$ Pollen deposition · Pollen removal · Pollination

\section{Introduction}

Different floral visitors affect pollination of flowers in different ways depending on their relative size, visit frequency and behaviour. "The most effective pollinator" principle formulated by Stebbins (1970; p. 318) implies that floral characters should evolve to match "the most frequent and effective" visitor. When we look at various metrics used to quantify pollinator performance (presented and/or reviewed in, e.g., Kearns and Inouye 1993; Dafni et al. 2005; Fenster et al. 2004; Ne'eman et al. 2010), we may distinguish between a "quantitative" and "qualitative" component of animal activity, where quality determines animal's ability to deliver pollen grains to conspecific stigmas, and quantity usually refers to the frequency of visits to a particular plant species (Herrera 1987; Olsen 1997). These two components of insect effectiveness (sensu Willmer 2011) are independent because rare visitors may carry more pollen than the common ones or vice versa (e.g. Mayfield et al. 2001; FumeroCabán and Meléndez-Ackerman 2007; Zych 2007; Niemirski and Zych 2011). In some cases, the most frequent visitor 
is indeed the most important pollinator (Motten et al. 1981; Fishbein and Venable 1996; Olsen 1997; Sahli and Conner 2007; Niemirski and Zych 2011), but in other cases, common floral visitors do not contribute significantly to pollination because, for example, they carry no or little pollen on their bodies (Schemske and Horvitz 1984; Zych 2002; FumeroCabán and Meléndez-Ackerman 2007; Watts et al. 2012), their efficiency in pollen transfer is low when compared to other animals (Wilson and Thomson 1991; Cane et al. 1993; Mayfield et al. 2001; Thomson and Goodell 2001; Javorek et al. 2002; Adler and Irwin 2006), and they preferentially visit one flower sexual phase in dioecious or dichogamous plants (Bierzychudek 1987; Schlessman et al. 2004; Larsson 2005; Davila and Wardle 2007; Zych 2007). Honey bees (Apis mellifera L.), for instance, being the most common floral visitors in many anthropogenic habitats, may be efficient in pollen removal, but inefficient in pollen deposition, and thus are quoted in some cases as parasites rather than actual pollinators (Westerkamp 1991; Wilson and Thomson 1991; Buchmann and Nabhan 1996; Willmer 2011; Ollerton et al. 2012). Also, the particular components of effectiveness of main floral visitors may be highly variable among years and/or sites (Ollerton 1996; Gómez and Zamora 1999; Lamborn and Ollerton 2000; Ivey et al. 2003; Gibson et al. 2006; Ollerton et al. 2007; Davila and Wardle 2008; Lay et al. 2011; Robertson and Leavitt 2011).

In many cases, precise determination of insects' effectiveness components seems difficult or unfeasible. This, for instance, may be related to, so-called, generalist pollination systems, where flowers are visited by dozens or even hundreds of insect species from many taxonomic orders and the evaluation of each taxon is a daunting task (Lindsey 1984; Herrera 1987; Olsen 1997; Gómez and Zamora 1999; Zych 2002, 2007; Gibson et al. 2006; PérezBañón et al. 2007; Niemirski and Zych 2011; Tepedino et al. 2011), or to cases where visitation frequency is low so that adequate sampling in field conditions is logistically impossible (e.g. Ollerton et al. 2009; Zych and Stpiczyńska 2012). Frequently in such cases, indirect methods are used to give an overview of the plant's pollination system (e.g. Lindsey 1984; Lamborn and Ollerton 2000; Zych 2002, 2007; Gibson et al. 2006; Ferrero et al. 2011; Horsburgh et al. 2011; Niemirski and Zych 2011; Tepedino et al. 2011). Although such methods usually include a combination of quality and quantity measures of animal performance on flowers (e.g. number/frequency of visits, insect relative abundance, body pollen load, foraging behaviour), they have some restrictions as, for instance, body pollen loads are not necessarily good estimates of pollen deposition (Adler and Irwin 2006). Also, they do not allow for the estimation of costs of pollination, for instance, in terms of pollen picked up by floral visitors, but not deposited on stigmas. At best, results based on such estimates should be treated as provisional until supported by more direct methods, for example, measuring pollen loads deposited on a stigma by a given pollinator species, or seed set after visits by certain pollen-carrying vectors or after exclusion of a given insect visitor (Johnson and Steiner 2000; Pellmyr 2002; Willmer 2011). The knowledge on the actual pollen dynamics and pollinator effectiveness may be of great importance especially in the case of threatened plant species where pollination and seed production often represent most vulnerable stages of the species' life history (Schemske et al. 1994; Kwak and Bekker 2006). Therefore, in the present study, we focused on red-listed Fritillaria meleagris (Liliaceae), reputedly classic bumblebee flower (Knuth 1899). In a 4-year study, Zych and Stpiczyńska (2012) reported bumblebees as the key pollinators of the plant based on indirect methods of assessing insect efficiency (insect body pollen loads and visit frequency). Bombus queens do carry Fritillary pollen on their bodies, are much more frequent visitors than other bees and visit flowers in poor weather conditions. However, small solitary bees of the genera Andrena and Lasioglossum carried almost three times larger pollen loads than bumblebees or honeybees, suggesting they could be more effective pollinators, at least in terms of quality. Therefore, to assess the quality component of pollinator effectiveness directly for floral visitors to $F$. meleagris and their pollen transfer efficiency, we performed a garden experiment, where we quantified pollen deposition and removal during single flower visits to the plant.

\section{Materials and methods}

\section{The plant}

In natural conditions, flowers of Fritillaria meleagris L. (Liliaceae) last 6-7 days, and they are produced singly (very rarely 2-3 per plant; Fig. 1) and offer both pollen and abundant, highly concentrated nectar produced throughout the life of a flower (Stpiczyńska et al. 2012). The flowers are from purplish pink to pure white with characteristic checkerboard pattern (Knuth 1899). The flowers contain six anthers and one three-carpellate pistil producing, on average, $148 \pm 26$ ovules (mean \pm SD; Stpiczyńska and Zych, unpublished). The plant is self-compatible, but seeds in natural conditions are mostly xenogamous (Zych and Stpiczyńska 2012). Flower visitors include bumblebees, honeybees, solitary bees and flies (Hedström 1983; Zych and Stpiczyńska 2012). Published estimates of the plant pollination system based on visitation data (Knuth 1899) or indirect measures of insects' effectiveness (Hedström 1983; Zych and Stpiczyńska 2012) report bumblebees as the main pollinators. 
The experiment

Our experimental work was completed during April 2010. We created a small artificial population of $F$. meleagris $\mathrm{L}$. (Liliaceae) in the Botanic Garden, University of Warsaw, located in Warsaw, Central Poland, on the western bank of the Vistula river valley, E2 $1^{\circ} 1^{\prime} 49^{\prime \prime} \mathrm{N} 52^{\circ} 13^{\prime} 15^{\prime}, 110 \mathrm{~m}$ a.s.l. (Werblan-Jakubiec 1991). In the fall of 2009, we planted approximately 500 plants in a $500-\mathrm{m}^{2}$ grassy area in the garden. The plants were grown from commercially available bulbs (Domena, Łomianki, Poland). These served as a source of flowers for the study.

Our experiment was conducted for 5 days in a small grassy garden compartment (approximately $100 \mathrm{~m}^{2}$; hereafter experimental garden), isolated from other parts of the garden. It was situated approximately $300 \mathrm{~m}$ from the source artificial population, in which prior to experimental work we bagged flower buds. To saturate pollinator community, and to find out whether Apis mellifera is indeed an effective pollinator, we placed there a small beehive and a commercially available colony of Bombus terrestris (Polski TrzmielMarcin Matuszak, Tymieniec-Dwór 8; 62-865 Szczytniki,

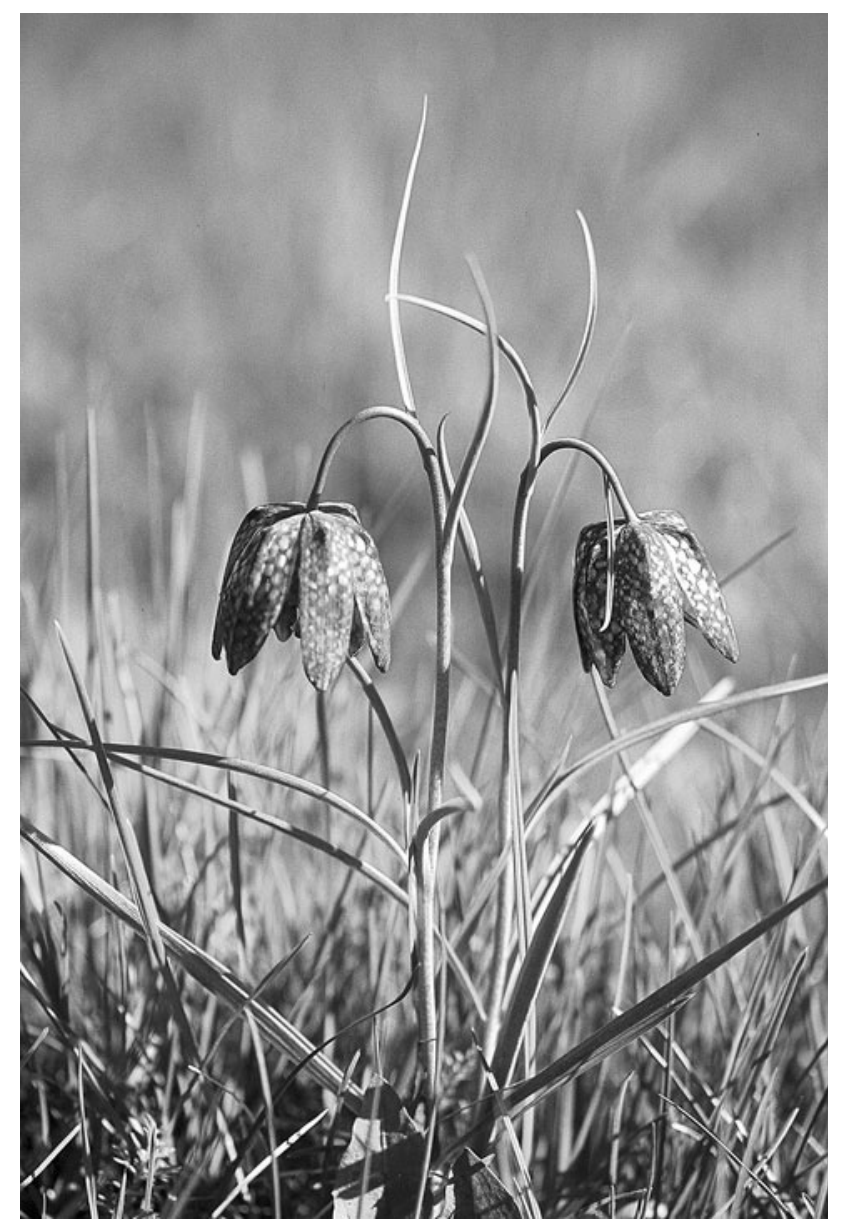

Fig. 1 Fritillaria meleagris L. (Liliaceae). Photograph by M. Zych
Poland). Before the experiment took place, we had mowed the area trying to remove all the flowers from the neighbour herb plants (mostly of Corydalis solida, Ficaria verna, Gagea lutea and Taraxacum sp.) and established there a regular $10 \times 5$ grid composed of glass test tubes with water, fastened to thin wooden sticks, where each time we presented 50 cut stems with open, unbagged flowers in the stage of pollen presentation. Most of the stems used in the experiment bore a single flower, and no more than $5 \%$ of stems had two flowers. Half of the stems (25) were intended as "adaptation plants". Insects were allowed to freely forage on adaptation plants for approximately 2 days before the experiment to gain experience with a novel flower type. The remaining 25 stems were treated as experimental. Virgin flowers were unbagged each day at approximately $09.00 \mathrm{~h}$ and, if not visited, again bagged at approximately $18.00 \mathrm{~h}$, and adaptation plants remained available for insects throughout the whole period of the study. After a single visit to an experimental flower (i.e. an insect contacted floral reproductive parts), it was collected, its stigmas and anthers removed, and stored separately in Eppendorf tubes in $70 \% \mathrm{EtOH}$. We noted the identity of insect visitors, and in order to check for possible relationship between visit duration and pollen deposition or removal, for 3 days of the experiment also duration of the visits (measured from the moment of entering the flower until departure). In order to distinguish among pollen- and nectar visits, we observed insect's behaviour in a flower. Whenever an insect clung to a sepal and, facing the nectary, moved upwards, we treated that as a nectar visit, and other behaviour was regarded as seeking pollen. Collected flowers were immediately replaced with new virgin ones. Each day, as the control for both pollen removal and deposition, we would also collect in the same way stigmas and anthers from 3 to 5 random flowers treated in the same way as those used in the experiment (i.e. bagged and unbagged).

To measure pollen deposition on stigmas, each stigma exposed to a single insect visit was softened with $40 \%$ $\mathrm{NaOH}$ in a heated bath for 10 min (temperature approximately $60{ }^{\circ} \mathrm{C}$ ), rinsed in distilled water, placed on a microscopic slide in a drop of glycerin, covered with cover slips and gently pressed to distribute the macerated tissue over the whole slide. The number of Fritillaria pollen grains was counted under a light microscope (magnification $\times 40$ ). The initial tube where the stigma was deposited in ethanol was shaken and its content was poured onto one or more microscopic slides covered with cover slip, and again all Fritillaria pollen grains counted. The results of the two procedures were summed and used as estimate of pollen deposition.

To estimate pollen production per flower (in control flowers) or pollen remaining after the single visit, the anthers from an individual flower were placed in a watch glass and pollen extracted from the anthers with a dissecting needle and flushed into another watch glass with 
$50 \% \mathrm{EtOH}$ with a drop of tensioactive liquid (Dafni et al. 2005). After drying, the pollen was suspended in 1,500 $\mu \mathrm{l}$ of $66 \%$ glycerine; $10 \mu \mathrm{l}$ subsamples of the suspended pollen were counted under a light microscope. Two subsamples per flower were counted, and the results were extrapolated to obtain the number of pollen grains in the entire sample.

To estimate the pollinator efficiency of floral visitors (sensu Ivey et al. 2003), for each taxon, we compared mean pollen deposited relative to pollen removed.

We compared pollen deposition and removal among visitor taxa using ANOVA followed by post hoc pairwise tests (Statistica 7.1; Stat Soft Inc. 2005, Tulsa, OK, USA). Data were log-transformed to achieve normality. Visit duration could not be normalized by transformation and was tested using Kruskal-Wallis nonparametric ANOVA.

\section{Results}

During 5 days of experiment, we observed 96 individual visits to $F$. meleagris flowers by five insect species from two hymenopteran families, differing in size and behaviour [Andrenidae: Andrena sp.; Apidae: Anthophora plumipes (Pall.), Bombus lapidarius (L.), B. ruderarius (Müller), B. terrestris (L.)]. Bombus species recorded during the experiment represented two tongue-length classes (shorttongued $B$. terrestris and B. lapidarius and medium-tongued B. ruderarius; Goulson et al. 2008b), and we, however, observed no significant differences in performance among these species and therefore in subsequent analyses treat them together as one functional group. Bumblebees made over $81 \%$ of the visits, Andrena made $13 \%$ and A. plumipes $6 \%$ (the latter, for simplicity, hereafter referred to as Anthophora). Honeybees never visited the flowers, although occasionally they approached flowers and even rested on outer part of the perianth. Bumblebee visits were by large wild queens (body length approximately $20 \mathrm{~mm}$ ) and not by small workers from our introduced colony (body length approximately $15 \mathrm{~mm}$ ), and Anthophora were only by males (body length approximately $15 \mathrm{~mm}$ ). Bumblebees and large-bodied solitary bees (Anthophora) visited flowers for nectar, and small Andrena bees (body length less than $10 \mathrm{~mm}$ ) visited for pollen. The former two clung to sepals and departed from the flowers with visible pollen loads located on the thorax, while the latter wandered over the androecium and usually left flowers with pollen grains completely covering all body surfaces.

Insects from all groups deposited significantly more pollen than was found on unvisited control flowers (ANOVA on log-transformed data $F_{3,111}=14.49$, $P \ll 0.001$ ), but they did not differ significantly from each other in pollen deposition on virgin stigmas (Fig. 2).
Unvisited flowers contained $340000 \pm 40300$ pollen grains (mean and SD), and a single visit resulted, on average, in removal of $18 \pm 139 \%, 29 \pm 130 \%$ and $37 \pm 127 \%$ pollen grains from the flower, respectively, for Andrena, Bombus and Anthophora (Fig. 3). Extremely large variation in the pollen removal data did not allow us to detect any significant differences among taxa or between each taxon and control flowers in the amounts of pollen grains remaining in a flower after a single visit (ANOVA on log-transformed data $F_{3,110}=0.46, P>0.7$ ).

Mean efficiency of pollen transfer was slightly but insignificantly higher for pollen-collecting Andrena $(7.6 \pm 60.0 \%)$ than for nectar-collecting Bombus $(5.8 \pm 25.6 \%)$ and Anthophora $(5.9 \pm 20.0 \%)$.

Time spent on flowers varied greatly among the insect groups (Kruskal-Wallis ANOVA: $\quad \mathrm{H}_{(2, \mathrm{~N}=46)}=7.87$; $P=0.0195)$, and bumblebees performed, on average, significantly shorter visits than Andrena individuals (mean and SD $43 \pm 51 /$ median 31 s vs. mean and SD $308 \pm 245 /$ median $195 \mathrm{~s} ; P=0.0175$, Kruskal-Wallis test for pairwise comparisons, Fig. 4), and equally long as Anthophora (mean and SD $53 \pm 41 /$ median 49 s).

\section{Discussion}

Fritillary in our experimental array at the botanic gardens was pollinated by overwintered bumblebee queens and solitary bees, similarly to those seen in field conditions (Hedström 1983; Zych and Stpiczyńska 2012).

In our study, all floral visitors deposited similar amounts of pollen in F. meleagris flowers. Therefore, despite the

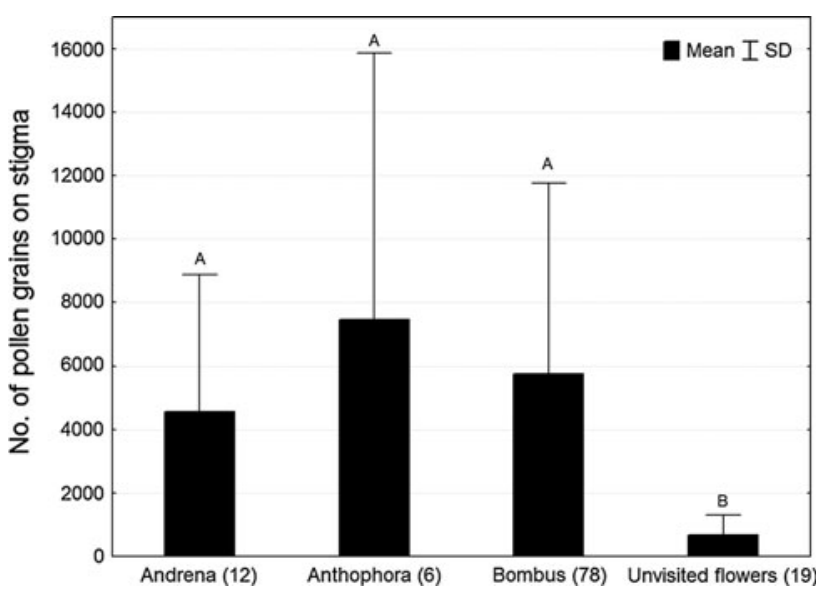

Fig. 2 Average number of Fritillaria meleagris pollen grains (and SD) deposited on the virgin stigma after a single visit by Andrena, Anthophora or Bombus, as compared to stigmatic loads in unvisited flowers (control). Numbers in brackets indicate sample size for each group. Means with different letter are different at $P<0.05$ (post hoc Tukey HSD test for uneven N) 


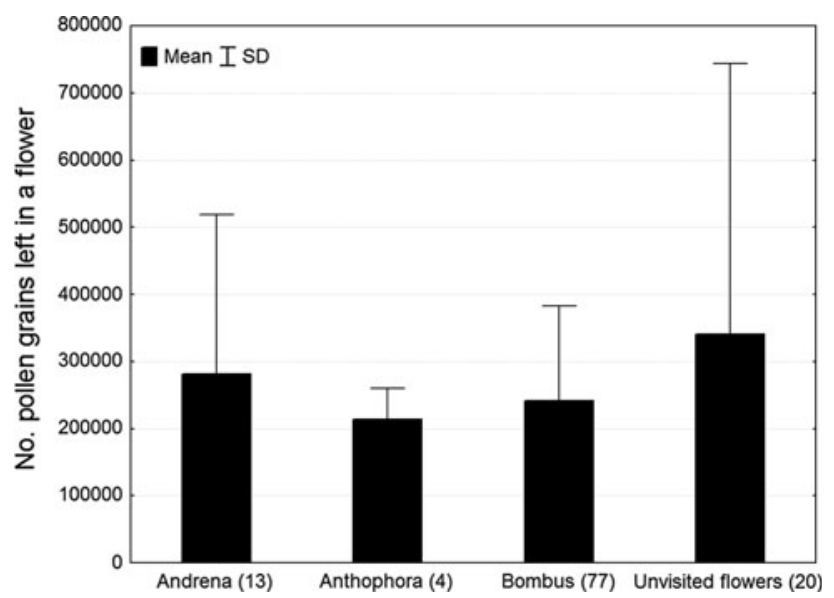

Fig. 3 Number of pollen grains (and SD) left in a Fritillaria meleagris flower after a single visit by Andrena, Anthophora or Bombus. The results for insect-visited flowers are not significantly different from those for unvisited flowers (control; ANOVA on logtransformed data, $\left.F_{3,110}=0.46, P>0.7\right)$. Numbers in brackets indicate sample size for each group

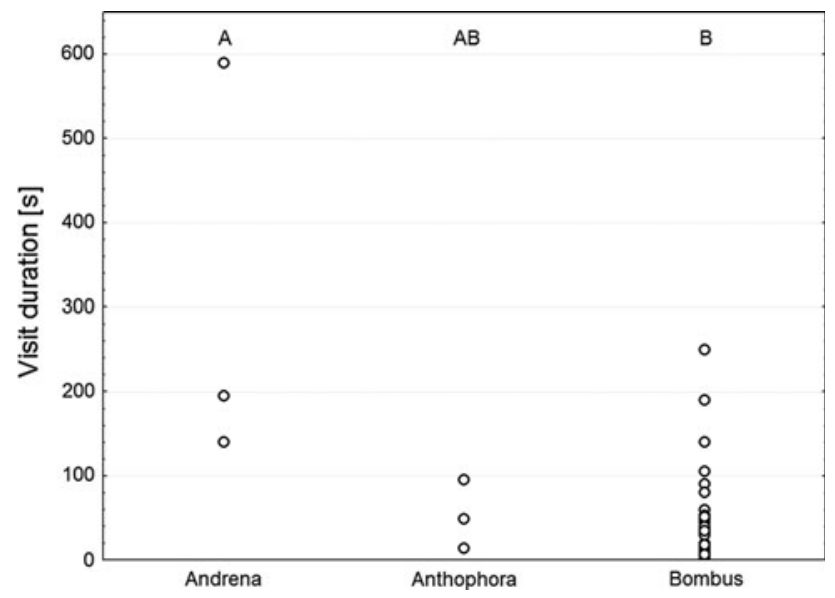

Fig. 4 Visit duration of the main pollinators in Fritillaria meleagris flowers. Median values are as follows: Andrena 195, Anthophora 49, Bombus 31, and differ significantly among the taxa (Kruskal-Wallis ANOVA: $\mathrm{H}_{2, \mathrm{~N}=4}=7.87 ; P<0.05$ ). The same letters over the data points indicate that medians are not significantly different at $P<0.05$ (Kruskal-Wallis test for pairwise comparisons)

differences in body size and flower-visitor behaviour, all floral visitors were similar in the quality component of effectiveness (sensu Olsen 1997). We also observed substantial differences between flower visitors in pollen removal but due to high variation of the results we found them to be statistically insignificant. Interestingly, Sahli and Conner (2007) found a similar lack of effect of body size on removal, but significant differences between nectar and pollen foragers in a study on wild radish. Such differences were also reported by Wilson and Thomson (1991) in a study of Impatiens capensis (Balsaminaceae), where nectar foraging Bombus removed relatively small amounts of pollen and deposited much of it compared to pollen foraging A. mellifera and solitary bees. When, for the same plant species, the foraging mode was changed and both key visitors (Bombus and A. mellifera) sought nectar, the difference between taxa disappeared (Young et al. 2007). In the present experiment, we also observed differences in foraging behaviour of pollinators. Bumblebee queens and Anthophora males foraged for nectar and Andrena for pollen in Fritillary flowers. This, however, did not alter their pollen removal and deposition. If all visitors to Fritillary flowers sought nectar, most likely it would result in inferior performance of Andrena, which were the smallest, in terms of body size, of the three observed visitor groups. Fritillary produces rather large, pendant flowers, and when seeking nectar, insects cling to sepals and move upwards, where the nectaries, running along the middle nerve, are situated. In doing so, they receive pollen, which is deposited mostly on the upper side of thorax and wings (Knuth 1899; Hedström 1983). Both Anthophora and Bombus are large enough to touch anthers and stigma while using nectar, whereas Andrena individuals are markedly smaller and could probably collect nectar without touching floral sexual parts. Our results show, however, that regardless of the character of a visit, any floral visitor entering the flower, in search for either pollen or nectar, can successfully pollinate the stigma, and a single visit deposits sufficient pollen to fertilize all ovules. The large variation in estimated pollen removal (which probably may be attributed both to variation in pollen production per flower and crude sampling procedure with too few subsamples analysed) did not allow for reliable estimation of pollinator efficiency, but the fraction of pollen produced in a single Fritillary flower reaching conspecific stigma during a single visit seems similar for all insect visitors (1.3-2.2\%, depending on the insect taxon).

Insect visitors to Fritillary differed more dramatically in the quantity component of pollination. The dominance of Bombus pollinators (over $81 \%$ of visits) is consistent with data from the natural populations, where in some years, Bombus constitute $100 \%$ of floral visitors (Zych and Stpiczyńska 2012). Some researchers (e.g. Gómez and Zamora 1992; Morris 2003; Vázquez et al. 2005) argue that visitation rate could be a suitable surrogate of pollinator performance. Although attractive in terms of research methodology and concurrent with our present results, this suggestion seems true only provided the visitation is performed by animals that are equivalent in terms of the quality component of pollination. This equivalency is indeed the case for $F$. meleagris, but in other cases, such simplification could be misleading (see, e.g., Zych 2002, 2007; Fumero-Cabán and Meléndez-Ackerman 2007; Watts et al. 2012; Sánchez-Lafuente et al. 2012). Visit duration, although different among the three groups, did 
not translate to differences in pollen transfer. The shortest visits were by bumblebees and Anthophora males such that either of them can service approximately 6-7 times more flowers per unit time than Andrena bees. Longer visits of the latter, however, do not produce larger pollen deposition. We note that the results for Andrena and Anthophora are based on very low sample size, which limits the scope of inference.

Contrasting our results on pollen deposition to data on pollen carried on insect body from the natural population, we argue that body pollen loads, at least for Fritillary, are not necessarily good estimates of insect effectiveness in pollination. Small Andrena bees foraged for pollen in pendant flowers of $F$. meleagris, and sometimes, they leave the flower completely covered with pollen, which could explain large body pollen loads found by Zych and Stpiczyńska (2012) on these insects. This high pollen carriage did not imply significantly larger pollen deposition but, as suggested by these authors, could result in more self-pollen grains being delivered to the stigma. Also, in the field conditions, Andrena individuals (and honey bees) are reported as more opportunistic foragers, carrying more heterogeneous body pollen loads (over $82 \%$ of non-Fritillaria pollen; Zych and Stpiczyńska 2012). On the other hand, bumblebees and Anthophora seem to provide more direct transfer of pollen on thorax, which is left upon arrival in the next flower's stigma, and as shown by Zych and Stpiczyńska (2012) for in situ plants, body pollen loads carried by Bombus individuals are composed in more than $91 \%$ of Fritillary pollen. In the present study, however, we did not address the issue of the quality of pollen (its viability, compatibility, etc.) delivered by a given pollinator, which itself deserves further study.

In our study, pollinator effectiveness was similar for all flower visitors regardless of body size, and pollen transfer efficiency was only insignificantly higher for the smallest Andrena. Interestingly, Adler and Irwin (2006) also could not confirm their prediction that bee size is positively correlated with its pollen transfer ability. This, however, is not an universal trend, as the opposite was, for instance, reported by Snow and Roubik (1987) for Cassia and Howlett et al. (2011) for Brassica rapa var. chinensis. Pollen-collecting behaviour of Andrena can also, at least partly, explain the long duration of their visits, when compared to faster movements of large-bodied bumblebees and Anthophora foraging for nectar. The latter, however, are absent from all the natural populations studied so far, where, in turn, honeybees foraging on $F$. meleagris were observed (Hedström 1983; Zych and Stpiczyńska 2012). In the present study, although we placed a small beehive close to our experimental array, not a single honeybee visited $F$. meleagris flowers. This was probably because our experiment was conducted in early spring, so the colony included mostly experienced workers that would rather choose floral resources they were familiar with. Last, but not least, our experimental population could be too small for bees to switch from other kind of flowers.

Fritillaria meleagris is a rare and threatened species throughout its range (Schnittler and Günther 1999) and its populations are generally decreasing (Zych and Stpiczyńska 2012; and literature cited). Our results show that bumblebees are the most effective pollinators of $F$. meleagris, when both quality and quantity component of pollination is concerned; furthermore, they visit flowers (and therefore pollinate) even in bad weather conditions (Hedström 1983; Zych and Stpiczyńska 2012). Although these insects are generally declining in Central Europe (Kosior et al. 2007; Goulson et al. 2008a), the taxa present in our study belong to common species and the plant can be successfully pollinated also by other floral visitors, which suggests that its pollination biology cannot alone explain its rarity.

Acknowledgments We thank Małgorzata Bieńkowska, Beata Panasiuk and Darek Gerula from the Research Institute of Horticulture, Apicultural Division in Puławy for advice and help with the honeybee colony; Krysia Jędrzejewska-Szmek for help during the experiment; and Dorota Szubierajska for help with the bulb cultivation. Comments of Marcos Méndez, Jeff Ollerton, Neal Williams and two anonymous reviewers greatly improved the earlier versions of the manuscript. The study was financially supported by intramural grant BW 1755/69 from Faculty of Biology, University of Warsaw (to JG), and research grant N N304 131736 from the Polish Ministry of Science and Higher Education (to $\mathrm{MZ}$ and $\mathrm{MS}$ ).

Open Access This article is distributed under the terms of the Creative Commons Attribution License which permits any use, distribution, and reproduction in any medium, provided the original author(s) and the source are credited.

\section{References}

Adler LS, Irwin RE (2006) Comparison of pollen transfer dynamics by multiple floral visitors: experiments with pollen and fluorescent dye. Ann Bot 97:141-150

Bierzychudek P (1987) Pollinators increase the cost of sex by avoiding female flowers. Ecology 68:444-447

Buchmann SL, Nabhan GP (1996) The forgotten pollinators. Island Press, Washington D.C

Cane JH, Mackenzie K, Schiffhauer D (1993) Honey-bees harvest pollen from the porose anthers of cranberries Vaccinium macrocarpon (Ericaceae). Am Bee J 133:293-295

Dafni A, Kevan PG, Husband BC (2005) Practical pollination ecology. Enviroquest, Cambridge, Ontario

Davila YC, Wardle GM (2007) Bee boys and fly girls: do pollinators prefer male or female umbels in protandrous parsnip, Trachymene incisa (Apiaceae)? Aust Ecol 32:798-807

Davila YC, Wardle GM (2008) Variation in native pollinators in the absence of honeybees: implications for reproductive success of an Australian generalist-pollinated herb Trachymene incisa (Apiaceae). Bot J Linn Soc 156:479-490 
Fenster CB, Armbruster WS, Wilson P, Dudash MR, Thomson JD (2004) Pollination syndromes and floral specialization. Annu Rev Ecol Evol Syst 35:375-403

Ferrero V, Castro S, Sánchez J, Navarro L (2011) Stigma-anther reciprocity, pollinators, and pollen transfer efficiency in populations of heterostylous species of Lithodora and Glandora (Boraginaceae). Plant Syst Evol 291:267-276

Fishbein M, Venable DL (1996) Diversity and temporal change in the effective pollinators of Asclepias tuberosa. Ecology 77: 1061-1073

Fumero-Cabán JJ, Meléndez-Ackerman EJ (2007) Relative pollination effectiveness of floral visitors of Pitcairnia angustifolia (Bromeliaceae). Am J Bot 94:419-424

Gibson RH, Nelson IL, Hopkins GW, Hamlett BJ, Memmott J (2006) Pollinator webs, plant communities and the conservation of rare plants: arable weeds as a case study. J App Ecol 43:246-257

Gómez JM, Zamora R (1992) Pollination by ants: consequences of the quantitative effects on a mutualistic system. Oecologia 91:410 418

Gómez JM, Zamora R (1999) Generalization vs. specialization in the pollination system of Hormathophylla spinosa (Cruciferae). Ecology 80:796-805

Goulson D, Lye GC, Darvill B (2008a) Decline and conservation of bumble bees. Annu Rev Entomol 53:191-208

Goulson D, Lye GC, Darvill B (2008b) Diet breadth, coexistence and rarity in bumblebees. Biodivers Conserv 17:3269-3288

Hedström I (1983) Kungsängsliljans pollinationsekologi. Svensk Bot Tidskrift 77:313-325

Herrera CM (1987) Components of pollinator quality-comparative analysis of a diverse insect assemblage. Oikos 50:79-90

Horsburgh M, Semple JC, Kevan PG (2011) Relative pollinator effectiveness of insect floral visitors to two sympatric species of wild aster: Symphyotrichum lanceolatum (Willd.) Nesom and $S$. lateriflorum (L.) Löve \& Löve (Asteraceae: Astereae). Rhodora 113:64-86

Howlett BG, Walker MK, Rader R, Butler RC, Newstrom-Lloyd LE, Teulon DAJ (2011) Can insect body pollen counts be used to estimate pollen deposition on pak choi stigmas? N Z Plant Protect 64:25-31

Ivey CT, Martinez P, Wyatt R (2003) Variation in pollinator effectiveness in swamp milkweed, Asclepias incarnata (Apocynaceae). Am J Bot 90:214-225

Javorek SK, Mackenzie KE, Vander Kloet SP (2002) Comparative pollination effectiveness among bees (Hymenoptera: Apoidea) on lowbush blueberry (Ericaceae: Vaccinium angustifolium). Ann Entomol Soc Am 95:345-351

Johnson SD, Steiner KE (2000) Generalization versus specialization in plant pollination systems. Trends Ecol Evol 15:140-143

Kearns CA, Inouye DW (1993) Techniques for pollination biologists. University of Colorado Press, Nowot

Knuth P (1899) Handbuch der Blütenbiologie, II Band, 2. Teil, Lobeliaceae bis Gnetaceae. Verlag von Wilhelm Engelmann, Leipzig

Kosior A, Celary W, Olejniczak P, Fijał J, Król W, Solarz W, Płonka $P$ (2007) The decline of the bumble bees and cuckoo bees (Hymenoptera: Apidae: Bombini) of Western and Central Europe. Oryx 41:79-88

Kwak MM, Bekker RM (2006) Ecology of plant reproduction: extinction risks and restoration perspectives of rare plant species. In: Waser NM, Ollerton J (eds) Plant-pollinator interactions. The University of Chicago Press, Chicago, From specialization to generalization, pp 362-386

Lamborn E, Ollerton J (2000) Experimental assessment of the functional morphology of inflorescences of Daucus carota (Apiaceae): testing the 'fly catcher effect'. Funct Ecol 14: $445-454$
Larsson M (2005) Higher pollinator effectiveness by specialist than generalist flower-visitors of unspecialized Knauita arvensis (Dipsacaceae). Oecologia 146:394-403

Lay CR, Linhart YB, Diggle PK (2011) The good, the bad and the flexible: plant interactions with pollinators and herbivores over space and time are moderated by plant compensatory responses. Ann Bot 108:749-763

Lindsey AH (1984) Reproductive biology of Apiaceae.1. Floral visitors to Thaspium and Zizia and their importance in pollination. Am J Bot 71:375-387

Mayfield MM, Waser NM, Price MV (2001) Exploring the 'most effective pollinator principle' with complex flowers: bumblebees and Ipomopsis aggregata. Ann Bot 88:591-596

Morris WF (2003) Which mutualists are most essential? Buffering of plant reproduction against the extinction of pollinators. In: Kareiva P, Levin S (eds) The importance of species: perspectives on expendability and triage. Princeton University Press, Princeton, pp 260-280

Motten AF, Campbell DR, Alexander DE, Miller HL (1981) Pollination effectiveness of specialist and generalist visitors to North Carolina populations of Claytonia virginica. Ecology 62:1278-1287

Ne'eman G, Jurgens A, Newstrom-Lloyd L, Potts SG, Dafni A (2010) A framework for comparing pollinator performance: effectiveness and efficiency. Biol Rev 85:435-451

Niemirski R, Zych M (2011) Fly pollination of dichogamous Angelica sylvestris (Apiaceae): how (functionally) specialized can a (morphologically) generalized plant be? Plant Syst Evol 294:147-158

Ollerton J (1996) Reconciling ecological processes with phylogenetic patterns: the apparent paradox of plant-pollinator systems. J Ecol 84:767-769

Ollerton J, Stott A, Allnutt E, Shove S, Taylor C, Lamborn E (2007) Pollination niche overlap between a parasitic plant and its host. Oecologia 151:473-485

Ollerton J, Cranmer L, Stelzer R, Sullivan S, Chittka L (2009) Bird pollination of Canary Island endemic plants. Naturwissenschaften $96: 221-232$

Ollerton J, Price V, Armbruster WS, Memmott J, Watts S, Waser NW, Totland $\varnothing$, Goulson D, Alarcón R, Staout SC, Tarrant S (2011) Overplaying the role of honey bees as pollinators: a comment on Aebi and Naumann. Trends Ecol Evol 27:141-142

Olsen KM (1997) Pollination effectiveness and pollinator importance in a population of Heterotheca subaxillaris (Asteraceae). Oecologia 109:114-121

Pellmyr O (2002) Pollination by animals. In: Herrera CM, Pellmyr O (eds) Plant-animal interactions. An evolutionary approach, Blackwell, pp 157-184

Pérez-Bañón C, Petanidou T, Marcos-García MÁ (2007) Pollination in small islands by occasional visitors: the case of Daucus carota subsp. commutatus (Apiaceae) in the Columbretes archipelago Spain. Plant Ecol 192:133-151

Robertson I, Leavitt H (2011) Relative contributions to seed production by floral visitors of slickspot peppergrass, Lepidium papilliferum (Brassicaceae). Arthropod Plant Inter 5:379-389

Sahli HF, Conner JK (2007) Visitation, effectiveness, and efficiency of 15 genera of visitors to wild radish, Raphanus raphanistrum (Brassicaceae). Am J Bot 94:203-209

Sánchez-Lafuente A, Rodríguez-Gironés M, Parra R (2012) Interaction frequency and per-interaction effects as predictors of total effects in plant-pollinator mutualisms: a case study with the selfincompatible herb Linaria lilacina. Oecologia 168:153-165. doi: 10.1007/s00442-011-2084-z

Schemske DW, Horvitz CC (1984) Variation among floral visitors in pollination ability: a precondition for mutualism specialization. Science 225:519-521 
Schemske DW, Husband BC, Ruckelshaus MH, Goodwillie C, Parker IM, Bishop JG (1994) Evaluating approaches to the conservation of rare and endangered plants. Ecology 75:584-606

Schlessman MA, Underwood N, Watkins T, Graceffa LM, Cordray D (2004) Functions of staminate flowers in andromonoecious Pseudocymopterus montanus (Apiaceae, Apioideae). Plant Species Biol 19:1-12

Schnittler M, Günther KF (1999) Central European vascular plants requiring priority conservation measures-an analysis from national Red Lists and distribution maps. Biodivers Cons 8:891-925

Snow AA, Roubik DW (1987) Pollen deposition and removal by bees visiting two tree species in Panama. Biotropica 19:57-63

Stebbins GL (1970) Adaptive radiation of reproductive characteristics in angiosperms I: pollination mechanisms. Annu Rev Ecol Syst $1: 307-326$

Stpiczyńska M, Nepi M, Zych M (2012) Secretion and composition of nectar and the structure of perigonal nectaries in Fritillaria meleagris L. (Liliaceae). Plant Syst Evol 298:997-1013

Tepedino VJ, Bowlin WR, Griswold TL (2011) Diversity and pollination value of insects visiting the flowers of a rare buckwheat (Eriogonum pelinophilum: Polygonaceae) in disturbed and "natural" areas. J Poll Ecol 4(8):57-67

Thomson JD, Goodell K (2001) Pollen removal and deposition by honeybee and bumblebee visitors to apple and almond flowers. J Appl Ecol 38:1032-1044

Vázquez DP, Morris WF, Jordano P (2005) Interaction frequency as a surrogate for the total effect of animal mutualists on plants. Ecol Lett 8:1088-1094
Watts S, Ovalle DH, Herrera MM, Ollerton J (2012) Pollinator effectiveness of native and non-native flower visitors to an apparently generalist Andean shrub, Duranta mandonii (Verbenaceae). Plant Species Biol 27:147-158. doi:10.1111/j.14421984.2011.00337.x

Werblan-Jakubiec H (ed) (1991) Przewodnik po Ogrodzie Botanicznym Uniwersytetu Warszawskiego (University of Warsaw Botanic Garden guidebook). UNIWA, Warszawa

Westerkamp C (1991) Honeybees are poor pollinators-why? Plant Syst Evol 177:71-75

Willmer P (2011) Pollination and floral ecology. Princeton University Press, Princeton and Oxford

Wilson P, Thomson JD (1991) Heterogeneity among floral visitors leads to discordance between removal and deposition of pollen. Ecology 72:1503-1507

Young HJ, Dunning DW, Hasseln KW (2007) Foraging behavior affects pollen removal and deposition in Impatiens capensis (Balsaminaceae). Am J Bot 94:1267-1271

Zych M (2002) Pollination biology of Heracleum sphondylium L. (Apiaceae). The advantages of being white and compact. Acta Soc Bot Pol 71:163-170

Zych M (2007) On flower visitors and true pollinators: the case of protandrous Heracleum sphondylium L. (Apiaceae). Plant Syst Evol 263:159-179

Zych M, Stpiczyńska M (2012) Neither protogynous nor obligatory out-crossed: pollination biology and breeding system of the European Red List Fritillaria meleagris L. (Liliaceae). Plant Biol 14:285-294. doi:10.1111/j.1438-8677.2011.00510.x 